\title{
Sophoridine suppresses cell growth in human medulloblastoma through FoxM1, NF-אB and AP-1
}

\author{
ZHENSONG YUE ${ }^{1}$, TONGGUO $\mathrm{SI}^{2}$, ZHANYU PAN ${ }^{1}$, WENFENG CAO ${ }^{3}$, \\ ZHUCHEN YAN $^{1}$, ZHANSHENG JIANG $^{1}$ and HUAQIANG OUYANG ${ }^{1}$
}

\author{
Departments of ${ }^{1}$ Integrated Chinese and Western Medicine, ${ }^{2}$ Invasive Technology and ${ }^{3}$ Pathology, \\ Tianjin Medical University Cancer Institute and Hospital, Tianjin 300060, P.R. China
}

Received March 2, 2016; Accepted August 15, 2017

DOI: $10.3892 / \mathrm{ol} .2017 .7224$

\begin{abstract}
Sophoridine is an alkaloid extracted from Sophora alopecuroides that has extensive pharmacological actions. In the present study, the effect of sophoridine on cell growth of human medulloblastoma and its mechanism were investigated. Human medulloblastoma D283-Med cells were incubated with $0,0.5,1$ or $2 \mathrm{mg} / \mathrm{ml}$ sophoridine for 24 , 48 or $72 \mathrm{~h}$. Cell proliferation and cytotoxicity were analyzed using MTT and lactate dehydrogenase assays, respectively. Next, analyses of cell apoptosis and caspase-3/8 activity were performed using flow cytometry or spectrophotometry, respectively. Lastly, the change in FoxM1, TrkB, BDNF, $\mathrm{NF}-\kappa \mathrm{B}$ and AP-1 expression was investigated using western blot analysis. In the present study, treatment with sophoridine significantly suppressed cell growth and induced apoptosis in human medulloblastoma cells. In addition, sophoridine significantly increased cytotoxicity and caspase- $3 / 8$ activity in human medulloblastoma. Finally, it was found that sophoridine suppresses the protein expression of FoxM1, TrkB, BDNF NF- $\kappa$ B and AP-1 in human medulloblastoma cells. The present study suggests that sophoridine suppresses cell growth of human medulloblastoma through the inhibition of the FoxM1, NF- $\mathrm{kB}$ and AP-1 signaling pathway.
\end{abstract}

\section{Introduction}

Cerebral tumors are the second most common tumor in pediatric patients, with morbidity rate of $3.3 / 10,0000$ individuals in 2012 in China (1). Due to its poor prognosis, cerebral tumors are the leading cause of mortality in pediatric oncology (1). Medulloblastoma is a type of neuroepithelial tumor of the epencephalon, and is a common pediatric

Correspondence to: Dr Zhensong Yue, Department of Integrated Chinese and Western Medicine, Tianjin Medical University Cancer Institute and Hospital, Huan-Hu-Xi Road, He Xi District, Tianjin 300060, P.R. China

E-mail: youfu8050@163.com

Key words: sophoridine, medulloblastoma, FoxM1, NF-кB, AP-1 central nervous system tumor, with a morbidity rate of $25 \%$ and high paroxysmal age of 8 years (2). According to the reclassification of nervous system neoplasms by the World Health Organization in 2002, the types of medulloblastoma are classic medulloblastoma, pro-fibroplasia, maxicell/anaplasia and melanin. For classic medulloblastoma, tumor cells grow vigorously with little cytoplasm shown on histopathological examination (3). Statistics have shown that the survival time of $70 \%$ of patients reaches 5 years, while a certain high risk-patients have metastasis (4). Only $25 \%$ of these patients with metastasis have a survival time of 5 years (5).

Termed Forkhead box or winged helix domain, Forkhead box protein Ml (FOXM1) is an evolutionarily-conserved transcriptional regulatory factor family characterized by DNA binding domain (6). FOXM1 is a key regulator of the cell cycle. FOXM1 is expressed during the G1 and S phases in the cell cycle, and can regulate the transcription activity of numerous genes, including encoding cell division cycle (Cdc) 25A, Cdc25B, cyclin B, cyclin A, cyclin Dl, p21cip1, p27kipl, Aurora B kinase and Polo-like kinase 1. The loss of FOXM1 expression may lead to formation defects in the mitotic spindle and the delay of cell division, which may result in the failure of mitosis (7). FOXM1 is also associated with cell proliferation and apoptosis. A previous study has found that the signaling pathway of FOXM1 has an essential role in maintaining self-stability during cell developmental process (8). New evidence has indicated that FOXM1 has abnormal high expression in malignant cancers, such as lung cancer, spongioblastoma, prostatic cancer, hepatocellular carcinoma, primary breast carcinoma and pancreatic carcinoma (9). When altered using RNA interference, the expression of FOXM1 in the mammary gland and pancreatic cancer cells triggered the proliferation, metastasis, invasion, migration and inhibition of carcinoma cells (10).

As an important intranuclear transcription factor, the stress protein activator protein-1 (AP-1) directly participates in normal growth and carcinous conversion process while its functions in cells directly depend on cell types, the constituents of AP-1 and the relative proportion of different parts (11). The activity of AP-1 is closely associated with tumors. It can activate tumor-associated genes and promotes the occurrence and malignant evolution of tumors. AP-1 participates in cell proliferation, differentiation and conversion and has a fundamental role in tumor formation, metastasis and invasion (12). 
Sophoridine (Fig. 1) is an alkaloid that occurs in high levels in Sophora alopecuroides (13). Previous studies have identified that sophoridine reduced inflammatory responses caused by LPS $(14,15)$. It has pharmacological functions such as antitumor and anti-arrhythmia and affects the immune and central nervous systems (12). When used at an antitumor dosage, sophoridine can lower the heart rates of tested animals without affecting other indicators of the electrocardiogram or breathing (13). Therefore, the present study assessed the effect of Sophoridine on the suppression of cell growth in human medulloblastoma, which may provide an important biological basis for the pathogenesis of this disease.

\section{Materials and methods}

Cell culture. The human medulloblastoma D283-Med cell line was obtained directly from the Central Laboratory of Tianjin Medical University Cancer Institute and Hospital (Tianjin, China) and maintained in DMEM-Nutrient Mixture F-12 (DMEM/F12; Invitrogen; Thermo Fisher Scientific, Inc., Waltham, MA, USA) with human recombinant epidermal growth factor $(20 \mathrm{ng} / \mathrm{ml}), \mathrm{B}-27$ supplement (2\%; Invitrogen; Thermo Fisher Scientific, Inc.), supplemented with $10 \%$ fetal bovine serum (Invitrogen; Thermo Fisher Scientific, Inc.) and $1 \% 100 \mu \mathrm{g} / \mathrm{ml}$ penicillin/streptomycin solution at $37^{\circ} \mathrm{C}$ in a $5 \% \mathrm{CO}_{2}$ atmosphere.

Cell proliferation and cytotoxicity analysis. D283-Med cells $\left(5 \times 10^{4} / \mathrm{ml} ; 200 \mu \mathrm{l}\right)$ were added to a 96 -well plate and divided into groups treated with $0,0.5,1$ and $2 \mathrm{mg} / \mathrm{ml}$ sophoridine (Sigma-Aldrich; Merck KGaA, Darmstadt, Germany) for 24, 48 and $72 \mathrm{~h}$. Subsequently, $50 \mu \mathrm{l}$ MTT $(5 \mathrm{mg} / \mathrm{ml}$; Invitrogen; Thermo Fisher Scientific, Inc.) was added to the D283-Med cells and incubated for $4 \mathrm{~h}$ at $37^{\circ} \mathrm{C}$ in a $5 \% \mathrm{CO}_{2}$ atmosphere. MTT was removed and $150 \mu 1$ dimethyl sulfoxide was added and the plate was agitated for $20 \mathrm{~min}$. Lactate dehydrogenase (LDH; $60 \mu$ l; Thermo Fisher Scientific, Inc.) was added, and the plate was incubated for $30 \mathrm{~min}$ at $37^{\circ} \mathrm{C}$ in darkness. Cell proliferation and cytotoxicity were analyzed using a spectrophotometer (Tecan Sunrise Rainbow; Tecan Japan Co., Ltd., Tokyo, Japan) at $490 \mathrm{~nm}$.

Cell apoptosis analysis. D283-Med cells $\left(1 \times 10^{8} / \mathrm{ml} ; 2 \mathrm{ml}\right)$ were added to a 6 -well plate and divided into groups treated with $0,0.5,1$ and $2 \mathrm{mg} / \mathrm{ml}$ sophoridine for $48 \mathrm{~h}$. The D283-Med cells were incubated with $5 \mu 1$ annexin V-fluorescein isothiocyanate (Caltag Laboratories, Burlingame, CA, USA) and $5 \mu 1$ of propidium iodide (Caltag Laboratories) for $30 \mathrm{~min}$ at room temperature. Cells apoptosis was analyzed using the Guava easyCyte 5HT Flow Cytometer (Merck KGaA, Darmstadt, Germany).

Caspase-3/8 activity. D283-Med cells $\left(1 \times 10^{8} / \mathrm{ml} ; 2 \mathrm{ml}\right)$ were added to a 6 -well plate and divided into groups treated with 0 , $0.5,1$ and $2 \mathrm{mg} / \mathrm{ml}$ sophoridine for $48 \mathrm{~h}$. D283-Med cells were lysed on ice with $100 \mathrm{ml}$ pre-cooled cell lysis buffer (Beyotime Institute of Biotechnology, Haimen, China) for $30 \mathrm{~min}$. The protein concentration was determined by the bicinchoninic acid method (NE-PER; Thermo Fisher Scientific, Inc.). The substrates $10 \mu \mathrm{l}$ of Ac-DEVD-pNA (caspase-3; $2 \mathrm{mM}$; Beyotime
Institute of Biotechnology) and $10 \mu 1$ of Ac-IETD-pNA (caspase-8; $2 \mathrm{mM}$; Beyotime Institute of Biotechnology) were added to each well for $1 \mathrm{~h}$ at $37^{\circ} \mathrm{C}$. The activity of caspase- $3 / 8$ was analyzed using a spectrophotometer (Tecan Sunrise Rainbow; Tecan Japan Co., Ltd.) at $450 \mathrm{~nm}$.

Western blot analysis. D283-Med cells $\left(1 \times 10^{8} / \mathrm{ml} ; 2 \mathrm{ml}\right)$ were added to a 6-well plate and divided into groups treated with 0, 0.5, 1 and $2 \mathrm{mg} / \mathrm{ml}$ sophoridine for $48 \mathrm{~h}$. D283-Med cells were lysed on ice with $100 \mathrm{ml}$ pre-cooled cell lysis buffer for $30 \mathrm{~min}$. The protein concentration was determined by the bicinchoninic acid method (NE-PER; Thermo Fisher Scientific, Inc.). Protein samples were separated by SDS-PAGE on a 8-12\% gel and then transferred onto a polyvinylidene difluoride membrane (GE Healthcare, Little Chalfont, UK). After blocking with $5 \%$ non-fat milk for $1 \mathrm{~h}$, membranes were incubated with primary anti-FoxM1 (cat. no. sc-502; 1:500; Santa Cruz Biotechnology, Inc., Dallas, TX, USA), anti-TrkB (cat. no. sc-118; 1:500; Santa Cruz Biotechnology, Inc.), anti-BDNF (cat. no. sc-20981; 1:500; Santa Cruz Biotechnology, Inc.), anti-NF-кB (cat. no. sc-7178; 1:500; Santa Cruz Biotechnology, Inc.), anti-AP-1 (cat. no. ab21981; 1:1,000; Abcam, Cambridge, MA, USA) and anti- $\beta$-actin (cat. no. sc-7210; $1: 500$; Santa Cruz Biotechnology, Inc.) antibodies at $4^{\circ} \mathrm{C}$ overnight. After washing in Tris-buffered saline with Tween-20 (20 mM Tris-HCl, $150 \mathrm{mM} \mathrm{NaCl}$ and $0.05 \%$ Tween-20), the membranes were incubated with goat anti-rabbit IgG-horseradish peroxidase secondary antibodies (cat. no. sc-2004; 1:5,000; Santa Cruz Biotechnology, Inc.) at $37^{\circ} \mathrm{C}$ for $2 \mathrm{~h}$. Subsequent to this incubation, the membranes were visualized using a BeyoECL Plus (Beyotime Institute of Biotechnology).

Statistical analysis. The experimental data were presented as the mean \pm standard deviation and analyzed with SPSS 13.0 software (SPSS, Inc., Chicago, IL, USA). Statistical significance was determined by one-way analysis of variance followed by Tukey post hoc analysis. $\mathrm{P}<0.05$ was considered to indicate a statistically significant difference.

\section{Results}

Sophoridine suppresses cell growth of human medulloblastoma. To determine the effect of sophoridine on the growth of D283-Med cells, cell proliferation was measured using an MTT assay. As shown in Fig. 2, the proliferation of D283-Med cells was suppressed by treatment with sophoridine in a dose- and time-dependent manner. In particular, $2 \mathrm{mg} / \mathrm{ml}$ sophoridine significantly suppressed cell proliferation subsequent to treatment for 24,48 and $72 \mathrm{~h}, 1 \mathrm{mg} / \mathrm{ml}$ sophoridine significantly suppressed cell proliferation subsequent to treatment for $72 \mathrm{~h}$, and $0.5 \mathrm{mg} / \mathrm{ml}$ sophoridine significantly suppressed cell proliferation subsequent to treatment for $72 \mathrm{~h}$ in D283-Med cell.

Sophoridine is cytotoxic in human medulloblastoma. To study the effect of sophoridine on cytotoxicity of human medulloblastoma, a LDH assay was used to analyze the cytotoxicity of sophoridine on D283-Med cells. The results showed that treatment with 1 or $2 \mathrm{mg} / \mathrm{ml}$ sophoridine significantly induced cytotoxicity of D283-Med cells (Fig. 3). 


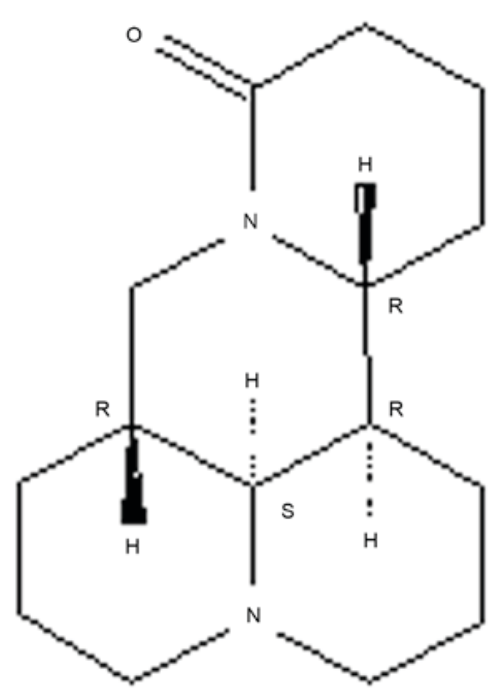

Figure 1. The chemical structure of sophoridine.

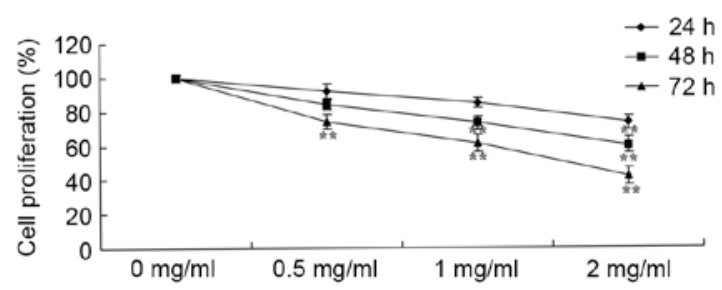

Figure 2. Sophoridine suppresses cell growth of human medulloblastoma cells. ${ }^{* *} \mathrm{P}<0.01$ vs. D283-Med cells incubated with $0 \mu \mathrm{M}$ sophoridine.

Sophoridine induces apoptosis in human medulloblastoma. To further study the effect of sophoridine on the apoptosis of human medulloblastoma cells, apoptosis rates were detected using flow cytometry. Fig. 4 showed that treatment with 1 or $2 \mathrm{mg} / \mathrm{ml}$ sophoridine significantly induced apoptosis in D283-Med cells, compared with control cells $(0 \mathrm{mg} / \mathrm{ml}$ sophoridine).

Sophoridine induces caspase-3/8 activity in human medulloblastoma. A Business kit was used to evaluate the effect of sophoridine on caspase-3/8 activity of human medulloblastoma in vitro subsequent to treatment for $48 \mathrm{~h}$. The representative results are shown in Fig. 5. Sophoridine (1 or $2 \mathrm{mg} / \mathrm{ml}$ ) significantly induced caspase-3/8 activity in D283-Med cells, compared with control cells $(0 \mathrm{mg} / \mathrm{ml}$ sophoridine).

Sophoridine suppresses FoxM1 protein expression in human medulloblastoma. To evaluate the effect of sophoridine on FoxM1 signal in human medulloblastoma, FoxM1 protein expression was recorded using western blot analysis. Sophoridine concentrations of 1 and $2 \mathrm{mg} / \mathrm{ml}$ concentrations were found to significantly suppress FoxM1 protein expression in D283-Med cells, compared with control cells $(0 \mathrm{mg} / \mathrm{ml}$ sophoridine; Fig. 6).

Sophoridine suppresses TrkB protein expression in human medulloblastoma. To further evaluate the effect of sophoridine

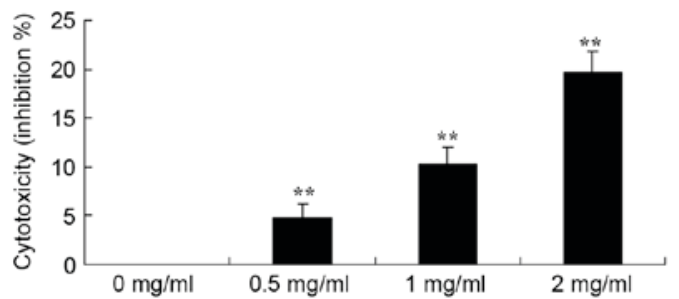

Figure 3. Sophoridine is cytotoxic in human medulloblastoma cells ${ }^{* *} \mathrm{P}<0.01$ vs. D283-Med cells incubated with $0 \mu \mathrm{M}$ sophoridine.

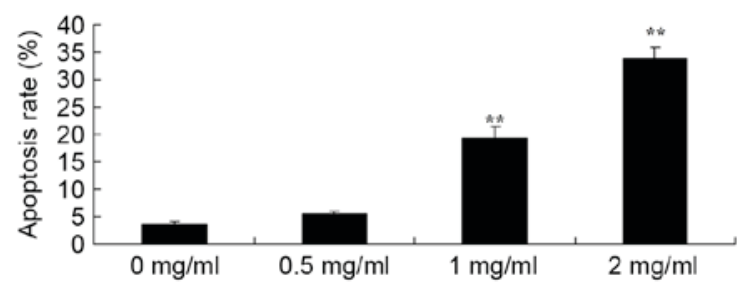

Figure 4. Sophoridine induces apoptosis in human medulloblastoma cells ${ }^{* *} \mathrm{P}<0.01$ vs. D283-Med cells incubated with $0 \mu \mathrm{M}$ sophoridine.

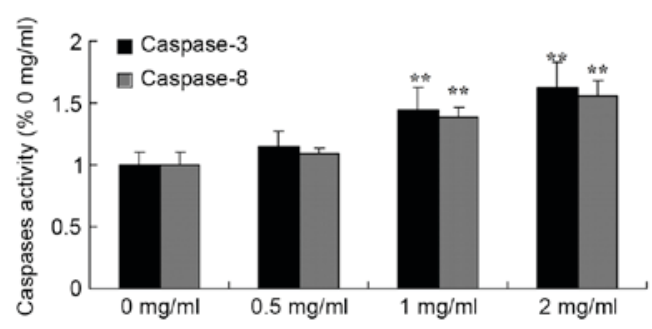

Figure 5. Sophoridine induces caspase-3/8 activity in human medulloblastoma cells. ${ }^{* *} \mathrm{P}<0.01$ vs. D283-Med cells incubated with $0 \mu \mathrm{M}$ sophoridine.

A

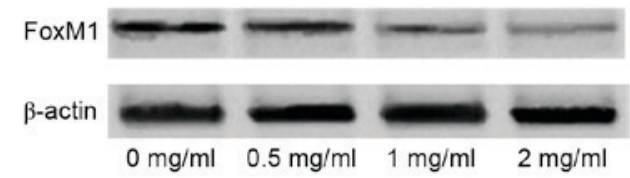

B

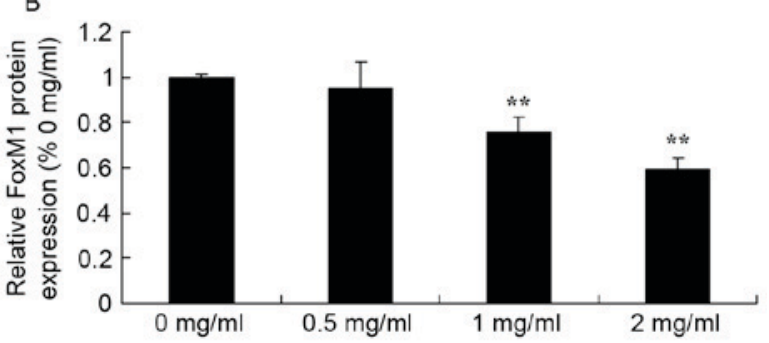

Figure 6. Sophoridine suppresses FoxM1 protein expression in human medulloblastoma cells, as shown using (A) western blot analysis and (B) statistical analysis of FoxM1 protein expression in human medulloblastoma D283-Med cells. ${ }^{* *} \mathrm{P}<0.01$ vs. D283-Med cells incubated with $0 \mu \mathrm{M}$ of sophoridine.

on TrkB signaling in human medulloblastoma, western blot analysis was used to detect TrkB protein expression in D283-Med cells. TrkB protein expression of D283-Med cells was significantly inhibited by 1 and $2 \mathrm{mg} / \mathrm{ml}$ of sophoridine, compared with control cells ( $0 \mathrm{mg} / \mathrm{ml}$ sophoridine; Fig. 7). 
A

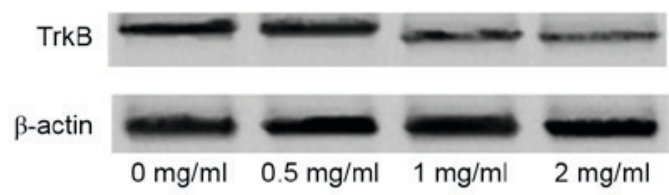

B

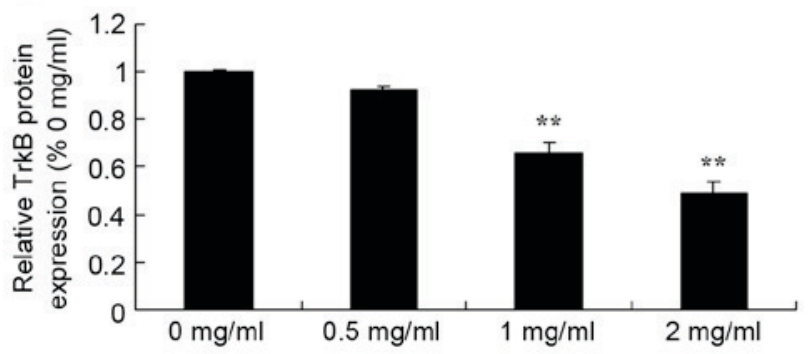

Figure 7. Sophoridine suppresses TrkB protein expression in human medulloblastoma cells, as shown using (A) western blot analysis and (B) statistical analysis of FoxM1 protein expression in human medulloblastoma D283-Med cells. ${ }^{* *} \mathrm{P}<0.01$ vs. D283-Med cells incubated with $0 \mu \mathrm{M}$ of sophoridine.

A

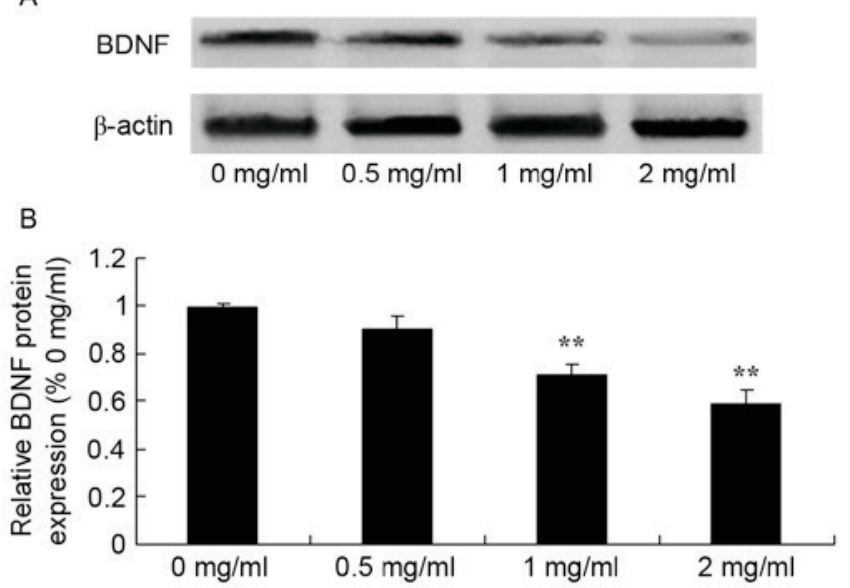

Figure 8. Sophoridine suppresses BDNF protein expression in human medulloblastoma cells, as shown using (A) western blot analysis and (B) statistical analysis of BDNF protein expression in human medulloblastoma D283-Med cells. ${ }^{* *} \mathrm{P}<0.01$ vs. D283-Med cells incubated with $0 \mu \mathrm{M}$ sophoridine.

Sophoridine suppresses BDNF protein expression in human medulloblastoma. To study the effect of sophoridine on BDNF signaling in human medulloblastoma, BDNF protein expression in D283-Med cells was measured using western blot analysis. The results showed that treatment with 1 and $2 \mathrm{mg} / \mathrm{ml}$ sophoridine significantly reduced BDNF protein expression in D283-Med cells, compared with control cells $(0 \mathrm{mg} / \mathrm{ml}$ sophoridine; Fig. 8).

Sophoridine suppresses $N F-\kappa B$ protein expression in human medulloblastoma. To further study the mechanism of sophoridine on cell growth of human medulloblastoma, changes in $\mathrm{NF}-\kappa \mathrm{B}$ protein expression were examined using western blot analysis. The present study also found that $\mathrm{NF}-\kappa \mathrm{B}$ protein expression in D283-Med cells was significantly suppressed by treatment with 1 and $2 \mathrm{mg} / \mathrm{ml}$ sophoridine, compared with control cells (0 mg/ml sophoridine; Fig. 9$)$.
A

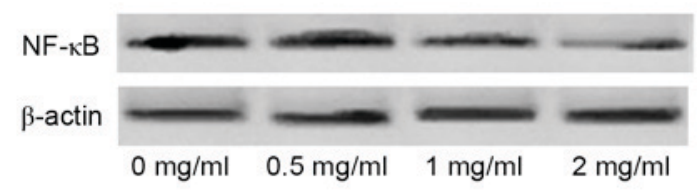

B

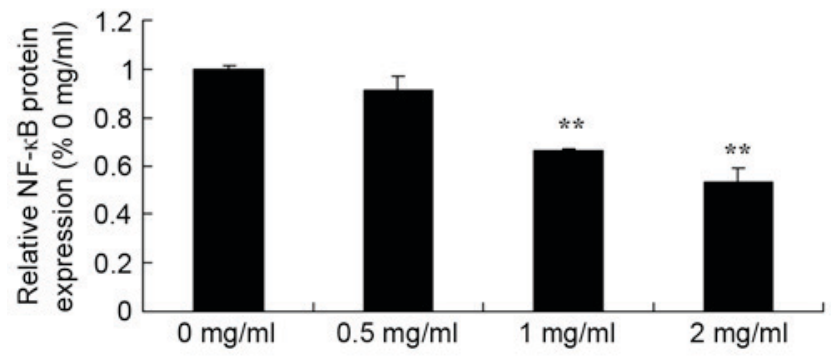

Figure 9. Sophoridine suppresses NF- $\mathrm{B}$ protein expression in human medulloblastoma cells, as shown using (A) western blot analysis and (B) statistical analysis of $\mathrm{NF}-\kappa \mathrm{B}$ protein expression (B) of human medulloblastoma. ${ }^{* *} \mathrm{P}<0.01$ vs. D283-Med cells incubated with $0 \mu \mathrm{M}$ of sophoridine.

A

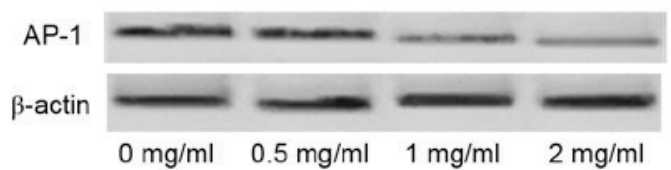

B

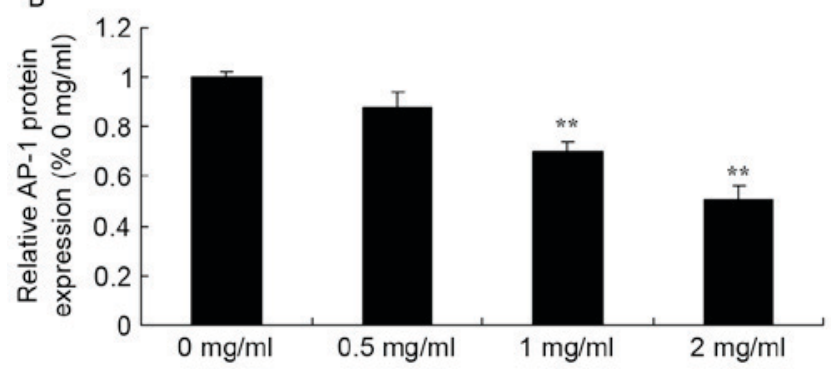

Figure 10. Sophoridine suppresses AP-1 protein expression in human medulloblastoma, as shown using (A) western blot analysis and (B) statistical analysis of AP-1 protein expression in human medulloblastoma. ${ }^{* *} \mathrm{P}<0.01$ vs. D283-Med cells incubated with $0 \mu \mathrm{M}$ sophoridine.

Sophoridine suppresses AP-1 protein expression in human medulloblastoma. Since one of the main mechanisms of sophoridine is its effect on AP-1 signaling in human medulloblastoma, the present study evaluated whether sophoridine affects AP-1 protein expression in D283-Med cells. As shown in Fig. 10, 1 and $2 \mathrm{mg} / \mathrm{ml}$ sophoridine significantly inhibited AP-1 protein expression in human D283-Med cells, compared with control cells ( $0 \mathrm{mg} / \mathrm{ml}$ sophoridine; Fig. 10).

\section{Discussion}

Medulloblastoma is an epithelial tumor of cerebellar neurocytes and is the most common central nervous system tumor in children (16). The morbidity of medulloblastoma accounts for $25 \%$ of pediatric brain tumors (17). The most common age is 8 years, and it mostly appears in patients $>20$ years old. According to statistics, the 5-year survival rate of patients 
is $70 \%$, but certain high-risk patients ( $<3$ years old) often present with metastasis, and the 5-year survival rate is $25 \%$ in 2012 in China (18). The present study showed that sophoridine suppresses cell growth, induces cytotoxicity and apoptosis and increased caspase-3/8 activity of human medulloblastoma. Wang et al (19) reported that sophoridine induces mitochondrial apoptosis through suppression of $\beta$-catenin/survivin signaling in cisplatin-resistant non-small cell lung cancer cells.

FOXM1 is a key regulator of the cell cycle and expressed during the G1, S and mitotic phases (9). A previous study suggested that FOXM1 could significantly downregulate the expression of P2cipi and P27kipi (7). During the transitional phase between $\mathrm{G} 2$ and $\mathrm{M}$, two downstream target genes of FOXM1 were found to promote NF- $\mathrm{NB}$ to participate in the progression of neurodegenerative diseases, such as Alzheimer's disease and Parkinson's disease (20). In the present study, it was found that sophoridine significantly suppressed FOXM1 protein expression in D283-Med cells. Wang et al (13) reported that sophoridine suppresses cell proliferation of human glioma U87MG cell line by upregulating the expression of caspase-3/8, $\mathrm{NF}-\kappa \mathrm{B}$ and AP-1.

The nuclear transcription factor NF- $\kappa \mathrm{B}$ is contains $\kappa \mathrm{B} \alpha$. In normal cells, $N F-\kappa B$ is located in the cytoplasm (21). Stimulated by extracellular functions, $\kappa \mathrm{B} \alpha$ can be degraded, which results in the activation of $\mathrm{p} 65$. The activation of $\mathrm{NF}-\kappa \mathrm{B}$ induces the expression of certain genes, including inflammatory factors, proliferation or pro-apoptosis factors (22). In the present study, it was also found that sophoridine significantly decreases the protein expression of NF- $\kappa \mathrm{B}$ in D283-Med cells. Li et al (23) reported that sophoridine inhibits cell proliferation through regulation of the NF- $\kappa \mathrm{B}$ signaling pathway in castration-resistant prostate cancer cells.

As target proteins of the TrkB/BDNF signaling pathway, $\mathrm{NF}-\kappa \mathrm{B}$ and FKHR are associated with FOXM1 (24). The functions of these proteins are associated with the survival, proliferation, invasion and metastasis (25). The interaction of FOXM1 with the TrkB/BDNF signaling pathway affects the biological behaviors of multiple myeloma cells. Previous studies have indicated that there is abnormal expression of TrkB/BDNF and FOXM1 in medulloblastoma, and the expression levels of these proteins are positively associated (26). The interaction between FOXM1 and TrkB/BDNF affects the apoptosis, cell cycle progression and proliferation of multiple myeloma cells (27). The present results showed that sophoridine suppressed TrkB and BDNF protein expression in D283-Med cells. Kan et al (28) reported that sophoridine protects neuro-axon from inflammation-induced injury through BDNF.

The AP-1 compound exerts its function by combining with genetic promoters (29). AP-1 is essential to the biological function of oncogenes, particularly participates in metastasis mediated by oncogenes. By importing TAM67 to inhibit the activity of AP-1, the invasiveness of squamous cell carcinoma in rats and humans can be markedly reduced (30). The results of the present study suggested that sophoridine suppressed the protein expression of $\mathrm{NF}-\kappa \mathrm{B}$ and AP-1 in D283-Med cell. Wang et al (13) reported that sophoridine suppresses cell proliferation of human glioma U87MG cell line through upregulating the expression of caspase-3/8, NF- $\kappa$ B and AP-1.

To conclude, the present findings demonstrated that sophoridine suppresses cell growth, induces cytotoxicity and apoptosis, and increases caspase-3/8 activity in human medulloblastoma. In addition, it was concluded that the FOXM1, $\mathrm{NF}-\kappa \mathrm{B}$ and AP-1 pathway has an important function in intracellular signaling in response to the anticancer effect of sophoridine in human medulloblastoma cells.

\section{References}

1. Robinson GW, Orr BA, Wu G, Gururangan S, Lin T, Qaddoumi I, Packer RJ, Goldman S, Prados MD, Desjardins A, et al: Vismodegib exerts targeted efficacy against recurrent sonic hedgehog-subgroup medulloblastoma: Results from phase ii pediatric brain tumor consortium studies PBTC-025B and PBTC-032. J Clin Oncol 33: 2646-2654, 2015.

2. Deutsch M, Thomas PR, Krischer J, Boyett JM, Albright L, Aronin P, Langston J, Allen JC, Packer RJ, Linggood R, et al: Results of a prospective randomized trial comparing standard dose neuraxis irradiation $(3,600 \mathrm{cGy} / 20)$ with reduced neuraxis irradiation $(2,340 \mathrm{cGy} / 13)$ in patients with low-stage medulloblastoma. A combined children's cancer group-pediatric oncology group study. Pediatr Neurosurg 24: 167-177, 1996.

3. Allen J, Donahue B, Mehta M, Miller DC, Rorke LB, Jakacki R, Robertson P, Sposto R, Holmes E, Vezina G, et al: A phase II study of preradiotherapy chemotherapy followed by hyperfractionated radiotherapy for newly diagnosed high-risk medulloblastoma/primitive neuroectodermal tumor: A report from the children's oncology group (CCG 9931). Int J Radiat Oncol Biol Phys 74: 1006-1011, 2009.

4. Cefalo G, Massimino M, Ruggiero A, Barone G, Ridola V, Spreafico F, Potepan P, Abate ME, Mascarin M, Garrè ML, et al: Temozolomide is an active agent in children with recurrent medulloblastoma/primitive neuroectodermal tumor: An Italian multi-institutional phase II trial. Neuro Oncol 16: 748-753, 2014.

5. Dhall G, Grodman H, Ji L, Gardner S, Dunkel IJ, McCowage GB, Diez B, Allen JC, Gopalan A, Cornelius AS, et al: Outcome of children less than three years old at diagnosis with non-metastatic medulloblastoma treated with chemotherapy on the 'Head Start' I and II protocols. Pediatr Blood Cancer 50: 1169-1175, 2008.

6. Ito T, Kohashi K, Yamada Y, Maekawa A, Kuda M, Furue M and Oda Y: Prognostic significance of Forkhead box M1 (FOXM1) expression and antitumor effect of FOXM1 inhibition in melanoma. Histopathology 69: 63-71, 2015.

7. Dai J, Yang L, Wang J, Xiao Y and Ruan Q: Prognostic value of FOXM1 in patients with malignant solid tumor: A meta-analysis and system review. Dis Markers 2015: 352478, 2015.

8. Zhao F and Lam EW: Role of the forkhead transcription factor FOXO-FOXM1 axis in cancer and drug resistance. Front Med 6: 376-380, 2012

9. Quan M, Wang P, Cui J, Gao Y and Xie K: The roles of FOXM1 in pancreatic stem cells and carcinogenesis. Mol Cancer 12: 159, 2013.

10. Shi M, Cui J and Xie K: Signaling of miRNAs-FOXM1 in cancer and potential targeted therapy. Curr Drug Targets 14: 1192-1202, 2013.

11. Chambers M, Kirkpatrick G, Evans M, Gorski G, Foster S and Borghaei RC: IL-4 inhibition of IL-1 induced Matrix metalloproteinase-3 (MMP-3) expression in human fibroblasts involves decreased AP-1 activation via negative crosstalk involving of Jun N-terminal kinase (JNK). Exp Cell Res 319: 1398-1408, 2013.

12. Uluckan O, Guinea-Viniegra J, Jimenez M and Wagner EF: Signalling in inflammatory skin disease by AP-1 (Fos/Jun). Clin Exp Rheumatol 33 (4 Suppl 92): S44-S49, 2015.

13. Wang WX, Sun ZH, Chen HM, Xu BN and Wang FY: Role and mechanism of Sophoridine on proliferation inhibition in human glioma U87MG cell line. Int J Clin Exp Med 8: 464-471, 2015.

14. Zhang B, Liu ZY, Li YY, Luo Y, Liu ML, Dong HY, Wang YX, Liu Y, Zhao PT, Jin FG and Li ZC: Antiinflammatory effects of matrine in LPS-induced acute lung injury in mice. Eur J Pharm Sci 44: 573-579, 2011.

15. Liou CJ, Lai YR, Chen YL, Chang YH, Li ZY and Huang WC: Matrine attenuates COX-2 and ICAM-1 Expressions in human lung epithelial cells and prevents acute lung injury in LPS-induced mice. Mediators Inflamm 2016: 3630485, 2016.

16. Gessi M, von Bueren AO, Rutkowski S and Pietsch T: p53 expression predicts dismal outcome for medulloblastoma patients with metastatic disease. J Neurooncol 106: 135-141, 2012. 
17. Camara-Costa H, Resch A, Kieffer V, Lalande C, Poggi G, Kennedy C, Bull K, Calaminus G, Grill J, Doz F, et al: Neuropsychological outcome of children treated for standard risk Medulloblastoma in the PNET4 european randomized controlled trial of hyperfractionated versus standard radiation therapy and maintenance chemotherapy. Int J Radiat Oncol Biol Phys 92: 978-985, 2015.

18. Palmer SL, Leigh L, Ellison SC, Onar-Thomas A, Wu S, Qaddoumi I, Armstrong GT, Wright K, Wetmore C, Broniscer A and Gajjar A: Feasibility and efficacy of a computer-based intervention aimed at preventing reading decoding deficits among children undergoing active treatment for medulloblastoma: Results of a randomized trial. J Pediatr Psychol 39: 450-458, 2014.

19. Wang HQ, Jin JJ and Wang J: Matrine induces mitochondrial apoptosis in cisplatin-resistant non-small cell lung cancer cells via suppression of $\beta$-catenin/survivin signaling. Oncol Rep 33: 2561-2566, 2015

20. Arora R, Yates C, Gary BD, McClellan S, Tan M, Xi Y, Reed E, Piazza GA, Owen LB and Dean-Colomb W: Panepoxydone targets NF-kB and FOXM1 to inhibit proliferation, induce apoptosis and reverse epithelial to mesenchymal transition in breast cancer. PLoS One 9: e98370, 2014.

21. Arslan S, Korkmaz Ö, Özbilüm N and Berkan Ö: Association

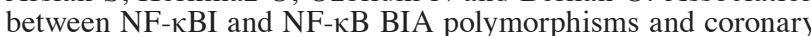
artery disease. Biomed Rep 3: 736-740, 2015.

22. Qian Y, Guan T, Huang M, Cao L, Li Y, Cheng H, Jin H and $\mathrm{Yu} \mathrm{D}$ : Neuroprotection by the soy isoflavone, genistein, via inhibition of mitochondria-dependent apoptosis pathways and reactive oxygen induced-NF- $\kappa \mathrm{B}$ activation in a cerebral ischemia mouse model. Neurochem Int 60: 759-767, 2012 .
23. Li Q, Lai Y, Wang C, Xu G, He Z, Shang X, Sun Y, Zhang F, Liu L and Huang H: Matrine inhibits the proliferation, invasion and migration of castration-resistant prostate cancer cells through regulation of the NF- $\mathrm{NB}$ signaling pathway. Oncol Rep 35: 375-381, 2016.

24. Kasemeier-Kulesa JC, Morrison JA, Lefcort F and Kulesa PM: TrkB/BDNF signalling patterns the sympathetic nervous system. Nat Commun 6: 8281, 2015.

25. Ghiglieri V, Sgobio C, Patassini S, Bagetta V, Fejtova A, Giampà C, Marinucci S, Heyden A, Gundelfinger ED, Fusco FR, et al: TrkB/BDNF-dependent striatal plasticity and behavior in a genetic model of epilepsy: Modulation by valproic acid. Neuropsychopharmacology 35: 1531-1540, 2010.

26. Turner BA, Sparrow J, Cai B, Monroe J, Mikawa T and Hempstead BL: TrkB/BDNF signaling regulates photoreceptor progenitor cell fate decisions. Dev Biol 299: 455-465, 2006.

27. Odate S, Nakamura K, Onishi H, Kojima M, Uchiyama A, NakanoK,KatoM,TanakaMandKatanoM:TrkB/BDNFsignaling pathway is a potential therapeutic target for pulmonary large cell neuroendocrine carcinoma. Lung Cancer 79: 205-214, 2013.

28. Kan QC, Lv P, Zhang XJ, Xu YM, Zhang GX and Zhu L: Matrine protects neuro-axon from CNS inflammation-induced injury. Exp Mol Pathol 98: 124-130, 2015.

29. Xu L, Ning H, Gu L, Wang Q, Lu W, Peng H, Cui W, Ying B, Ross CR, Wilson GM, et al: Tristetraprolin induces cell cycle arrest in breast tumor cells through targeting AP-1/c-Jun and NF-кB pathway. Oncotarget 6: 41679-41691, 2015.

30. Kuang H, Hua X, Zhou J and Yang R: Resolvin D1 and E1 alleviate the progress of hepatitis toward liver cancer in long-term concanavalin A-induced mice through inhibition of NF- $\mathrm{NB}$ activity. Oncol Rep 35: 307-317, 2016. 